\title{
Kajian Potensi Pengembangan Ekowisata Sebagai Upaya Konservasi Mangrove Di Desa Pasar Banggi, Kabupaten Rembang
}

\author{
Ghea Ken Joandani*, Rudhi Pribadi, Chrisna Adhi Suryono \\ Departemen IImu Kelautan, Fakultas Perikanan dan IImu Kelautan, Universitas Diponegoro \\ Jl. Prof.H.Soedarto S.H, Tembalang,Semarang, Jawa Tengah 50275 Indonesia \\ ${ }^{*}$ Corresponding author, e-mail : kenjoandani10@gmail.com
}

\begin{abstract}
ABSTRAK : Kawasan mangrove di Desa Pasar Banggi ditetapkan sebagai salah satu kawasan strategis dari sudut kepentingan fungsi dan daya dukung lingkungan hidup. Ekosistem mangrove di Desa Pasar Banggi merupakan salah satu yang terbaik di wilayah Pantura Jawa Tengah, sebelum dilakukan upaya rehabilitasi kondisi hutan mangrove di Desa Pasar Banggi mengalami kerusakan. Mengingat pentingnya fungsi hutan mangrove, maka sudah selayaknya dilakukan penanganan yang serius untuk mengurangi efek dari kerusakan ekosistem mangrove di Rembang ini. Salah satu alternative pemanfaatan yang memungkinkan untuk menjaga keutuhan ekosistem mangrove tersebut adalah melalui kegiatan ekowisata. Tujuan dari penelitian ini adalah untuk mengkaji potensi ekowisata mangrove di Pasar Banggi dan memberikan rekomendasi serta strategi pengembangan ekowisata di Pasar Banggi, Rembang. Metode yang digunakan dalam penelitian ini adalah deskriptif eksploratif. Metode pengumpulan data dengan menggunakan metode survei dalam bentuk data primer dan data sekunder. Data yang diperoleh dilakukan penentuan strategi pengembangan ekowisata mangrove dan analisis SWOT (Strength, Weakness, Opportunity, dan Threat). Hasil penelitian menunjukan bahwa faktor-faktor yang mempengaruhi pengembangan ekowisata mangrove di Desa Pasar Banggi adalah keragaman jenis mangrove, kualitas SDM dalam menangani wisatawan, ketersediaan SDA berkualitas untuk ekowisata dalam upaya konservasi, kebijakan dari pemerintah daerah terkait peraturan serta perundang-undangan tentang ekowisata hutan mangrove di Desa Pasar Banggi, kondisi sosial-ekonomi masyarakat, serta infrastruktur pendukung. Menurut analisi SWOT yang menjadi prioritas utama adalah: a) Peningkatan pengembangan ekowisata mangrove dalam bidang promosi program ekowisata dan penguatan institusi sebagai informasi ilmu pengetahuan ekosistem mangrove (Skor:4,52) dan b) Peningkatan partisipasi stakeholder terhadap pengembangan ekowisata mangrove yang berkelanjutan untuk peningkatan pelayanan terhadap pengunjung (Skor:3,29).
\end{abstract}

Kata Kunci: Ekowisata; Konservasi; Mangrove; Desa Pasar Banggi

\section{Study of Potential Ecotourism Development as Mangrove Conservation Efforts in Pasar Banggi Village, Rembang Regency}

ABSTRACT : The mangrove area in Pasar Banggi Village is designated as one of the strategic region, as the point of importance of function and living environmental support. Mangrove ecosystem in Pasar Banggi Village is the best one area in Pantura, Central Java. Actually, Pasar Banggi Village's condition was suffered damage before any efforts of rehabilitation of mangrove forest. Regarding the importance of the function of mangrove forests, there is a must doing a serious action to reduce the damage effects to the mangrove's ecosystem in Rembang. One of the utilization alternative that can be used to maintain the integrity of the mangrove ecosystem is through ecotourism activities. The purpose of this research is examining the potential of ecotourism in Pasar Banggi Village and giving recommendation with ecotourism development strategy. Method which is used in this research is explorative descriptive. The collecting data method using survey method in form of primary data and secondary data. Then take the decision about the mangrove ecotourism development strategy and SWOT (Strength, Weakness, Opportunity, and Threat) analysis, after the data were obtained. The research results shows that the factors that affects the mangrove ecotourism development in Pasar Banggi Village is kind of types of mangroves, human resources' quality while dealing with tourists or visitors, the availability 
of qualified nature resources for ecotourism, in effort of conservation, a policy of regional government related regulations and law about mangrove forest ecotourism in Pasar Banggi Village, community's socio-economic conditions, also supporting infrastructure. According to the SWOT analysis, the top concerning priority are: a) mangrove ecotourism raising development in the field of ecotourism program promotion and institution strengthening as the mangrove ecosystem knowledge information (Score: 4.52) and b) Raising stakeholders' participation toward the sustainable mangrove ecotourism development for improving service toward visitors (Score: 3.29)

\section{Keywords: Ecotourism; Conservation; Mangrove; Pasar Banggi Village}

\section{PENDAHULUAN}

Mangrove merupakan suatu varietas komunitas pantai tropis yang di dominasi oleh beberapa spesies pohon yang khas atau semak-semak yang mempunyai kemampuan untuk tumbuh dalam perairan asin. Mangrove mempunyai beberapa peran baik secara ekologi, fisik, maupun ekonomi yang sangat menunjang pemenuhan kebutuhan hidup manusia. Fungsi tersebut antara lain sebagai daerah pemijahan, pembesaran, penyedia pakan berbagai jenis ikan, udang, dan spesies lainnya. Selain itu, dengan sistem perakaran dan canopy yang rapat serta kokoh mampu meredam gelombang tsunami dan angin topan. Selama ini sebagian hutan mangrove dimanfaatkan untuk berbagai keperluan seperti pemukiman, pertambakan, budidaya perikanan dan sebagainya.

Indonesia memiliki mangrove yang terluas di dunia dan juga memiliki keragaman hayati yang terbesar serta strukturnya paling bervariasi. Di Indonesia perkiraan luas mangrove juga sangat beragam. Giesen (1993) menyebutkan luas mangrove Indonesia sekitar 2,5 juta hektar. Salah satu dari sumber yang mendapat perhatian di wilayah pesisir adalah ekosistem mangrove. Hutan mangrove sebagai sumber daya alam hayati mempunyai keragaman potensi yang memberikan manfaat bagi kehidupan manusia. Manfaat yang dirasakan berupa berbagai produk dan jasa. Pemanfaatan produk dan jasa tersebut telah memberikan tambahan pendapatan dan bahkan merupakan penghasilan utama dalam pemenuhan kebutuhan hidup masyarakat.

Salah satu jasa yang diperoleh dari manfaat hutan mangrove adalah berupa jasa ekowisata (Kustanti dan Yulia, 2005). Hutan mangrove sebagai suatu ekosistem mempunyai potensi keindahan alam dan lingkungan berupa komponen penyusun ekosistem yang terdiri dari vegetasi, biota atau organisme asosiasi, satwa liar, dan lingkungan sekitarnya. Fungsi lingkungan yang diperoleh dari hutan mangrove antara lain sebagai habitat, daerah pemijahan, penyedia unsur hara, dan lain sebagainya.

Penelitian ini dilakukan sebagai tindak lanjut dalam menyusun strategi yang tepat untuk mengembangkan ekowisata mangrove di daerah Pasar Banggi ini sehingga diharapkan dapat memberikan informasi yang baru dan melengkapi hasil penelitian -penelitian terdahulu. Adanya potensi yang besar di Pasar Banggi dalam pengelolaan ekosistem mangrove melalui kegiatan ekowisata mampu meningkatkan kesejahteraan masyarakat sekitar. Oleh karena itu, untuk dapat mengoptimalkan potensi sumberdaya dan lingkungan di kawasan hutan mangrove yang terletak di Pasar Banggi perlu dilakukan pengkajian, merekomendasikan arahan pengelolaan bagi pengembangan ekowisata mangrove dan menetukan strategi pengembangan berkelanjutan yang mampu berkembang secara optimal untuk dijadikan kawasan ekowisata.

\section{MATERI DAN METODE}

Materi yang digunakan dalam penelitian ini adalah data primer dan data sekunder. Dalam penelitian ini data primer yang digunakan adalah analisis/ observasi potensi fisik dan fauna ekowisata mangrove, sosial ekonomi masyarakat dan stakeholder, manajemen pengembangan ekowisata mangrove. Data sekunder yang digunakan adalah, data-data monografi, data ramalan pasang surut di perairan Kabupaten Rembang selama bulan Mei 2016, data rata-rata curah hujan bulanan di Kabupaten Rembang, penelusuran melalui internet berkaitan dengan informasi kewilayahan, serta dokumen-dokumen yang telah dipublikasikan oleh pihak-pihak terkait. 
Penelitian ini dilaksanakan di Desa Pasar Banggi, Kecamatan Rembang, Kabupaten Rembang. Metode yang digunakan dalam peneltian ini adalah metode deskriptif eksploratif. Pengumpulan data dilakukan dengan metode survei. Menurut Singarimbun (1989) penelitian survei adalah adalah penelitian yang mengambil sampel dari suatu populasi dan menggunakan kuisioner sebagai alat pengumpulan data yang pokok. Selanjutnya, analisis SWOT digunakan untuk menganalisis strategi Pengembangan ekowisata mangrove di Desa Pasar Banggi.

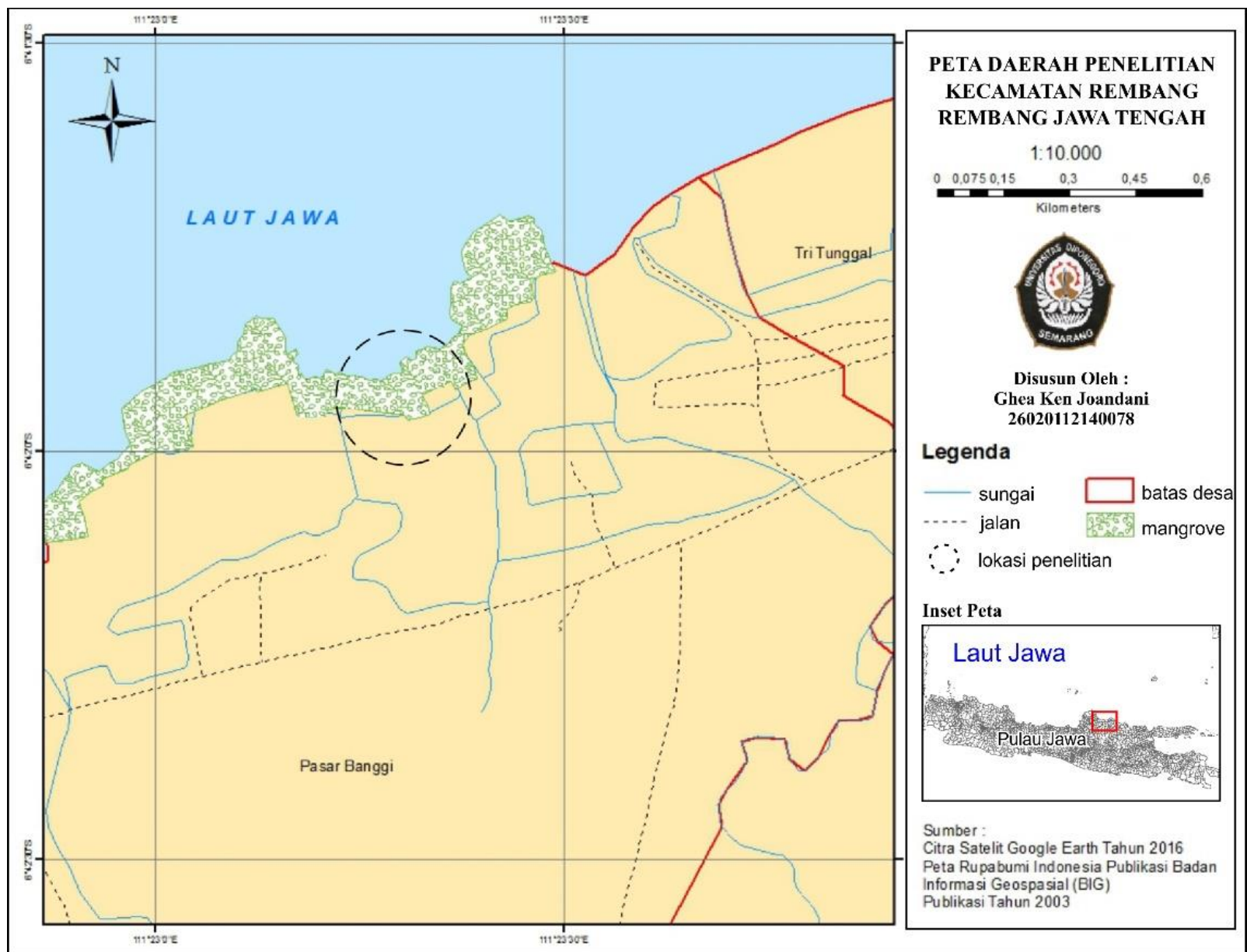

Gambar 1. Lokasi penelitian kawasan ekowisata mangrove Pasar Banggi, Kabupaten Rembang

\section{HASIL DAN PEMBAHASAN}

Kabupaten Rembang adalah kabupaten di Provinsi Jawa Tengah yang berbatasan dengan Laut Jawa di sebelah utara, Kabupaten Tuban ( Jawa Timur) di timur, Kabupaten Blora di selatan dan Kabupaten Pati di barat. Secara geografis Kabupaten Rembang terletak di ujung timur laut Jawa Tengah pada koordinat $111^{\circ} 00-111^{\circ} 30$ Bujur Timur dan $6^{\circ} 30-7^{\circ} 60$ Lintang Selatan. Bagian Selatan merupakan daerah perbukitan bagian dari pegunungan Kapur Utara dengan puncaknya Gunung Butak (679 meter), sebagian wilayah utara terdapat perbukitan dengan puncak Gunung Lasem (806 meter) dan sebagian merupakan wilayah pesisir. Desa Pasar Banggi termasuk ke dalam wilayah administrasi.

Hasil penelitian mengenai struktur vegetasi mangrove di Desa Pasar Banggi, secara keseluruhan menunjukkan bahwa lokasi ini didominasi oleh jenis Rhizophora sp. Hal ini ditunjukkan dengan tingginya Indeks Nilai Penting (INP) setiap spesies pada masing-masing lokasi dan nilai dominasinya pada tiap kategori pertumbuhan mangrove (pohon, anakan, semai).

Berdasarkan kategori pertumbuhan, rata-rata kerapatan mangrove kategori semai di Desa Pasar Banggi lebih tinggi dibandingkan dengan kategori pohon dan anakan. Rata-rata kerapatan mangrove kategori pohon di Pasar Banggi, Rembang berkisar 2.867 ind/ha yang tergolong 
mangrove dengan kerapatan tinggi dan padat. Begitu pula dengan kategori anakan (sapling) yang berkisar $2.933 \mathrm{ind} / \mathrm{ha}$, dimana tergolong kategori sangat tinggi. Sedangkan mangrove kategori semai (seedling) berkisar 20.000 ind/ha yang tergolong rendah.Fasilitas pendukung kawasan ekowisata mangrove Pasar Banggi, yang sudah ada, belum ada, atau dalam rencana pengadaan fasilitas dapat dilihat pada Tabel 1.

Partisipasi dari pengunjung merupakan faktor yang sangat penting dalam pengembangan ekowisata mangrove Untuk mengetahui partisipasi pengunjung dapat diketahui dari karakteristik masing-masing pengunjung yang merupakan ekowisatawan tersebut. dalam penelitian ini telah berhasil dicuplik beberapa karakteristik ekowisatan tersebut dari aspirasi dan persepsi ekowisatawan terhadap kasawasan pengembangan ekowisata mangrove. Partisipasi dari masyarakat merupakan faktor yang sangat penting dalam program ekowisata mangrove. Pengetahuan masyarakat akan fungsi dan manfaat ekosistem mangrove merupakan salah satu faktor keberhasilan pengembangan ekowisata mangrove. Keberhasilan rehabilitasi dan konservasi untuk pengembangan ekowisata mangrove di Desa pasar Banggi tidak terlepas dari partisipasi stakeholder yang ada disana, terutama dari partisipasi masyarakatnya yang dalam kehidupan sehari-harinya berhubungan dengan mangrove. Kelompok tani ini sudah mendukung kegiatan konservasi mangrove sejak tahun 1972. Partisipasi masyarakat yang tinggi ini dipengaruhi oleh adanya tokoh yang selalu mendorong masyarakat untuk terus berpartisipasi dan kelompok tani Sido Dadi Maju yang mendukung kegiatan konservasi mangrove serta peran pemerintah yang memberikan bantuan dalam kegiatan rehabilitasi, penyuluhan dan pelatihan tentang mangrove secara berkelanjutan

Berdasarkan faktor-faktor internal yaitu keuatan dan kelemahan juga faktor-faktor eksternal yaitu peluang dan ancaman. Faktor strategi internal yang dimiliki oleh kawasan mangrove di Pasar Banggi dengan kekuatan terbesar adalah faktor kondisi ekosistem mangrove yang sudah berjalan dengan bobot 0,306 . Kelemahan yang terbesar adalah Sarana dan prasarana kegiatan konservasi ekosistem mangrove dengan bobot 0,204. Faktor eksternal, yaitu dimana peluang terbesar adalah potensi kawasan ekowisata mangrove dengan bobot 0,278. Ancaman terbesar dengan bobot 0,224 adalah degradasi lingkungan.

Tabel 1. Sarana dan prasarana pendukung ekowisata mangrove di desa Pasar Banggi

\begin{tabular}{|c|c|c|c|c|c|}
\hline \multirow[t]{2}{*}{ No. } & Jenis & \multirow[t]{2}{*}{ Fasilitas } & \multicolumn{3}{|c|}{ Jenis Program } \\
\hline & Fasilitas & & Ada & Rencana & Rehab \\
\hline 1. & Sarana & Toilet/kamar mandi & $\sqrt{ }$ & - & - \\
\hline 2. & & Gazebo & $\sqrt{ }$ & - & - \\
\hline 3. & & Perahu (Kano) & $\sqrt{ }$ & - & - \\
\hline 4. & & Home Stay & $\sqrt{ }$ & - & - \\
\hline 5. & Pra sarana & Tempat Parkir & $\sqrt{ }$ & - & - \\
\hline 6. & & Tempat sampah & $\sqrt{ }$ & - & - \\
\hline 7. & & Tracking mangrove & $\sqrt{ }$ & - & - \\
\hline 8. & & Mushola & $\sqrt{ }$ & - & - \\
\hline 9. & & Pos Pengelola & $\sqrt{ }$ & - & - \\
\hline 10. & & Pos Tiket & $\sqrt{ }$ & - & - \\
\hline 11. & & $\begin{array}{l}\text { Rumah makan } \\
\text { apung }\end{array}$ & - & $\sqrt{ }$ & - \\
\hline 12. & & Resor Penginapan & - & $\sqrt{ }$ & - \\
\hline 13. & & $\begin{array}{l}\text { Anjungan } \\
\text { Penananaman } \\
\text { Mangrove }\end{array}$ & - & $\sqrt{ }$ & - \\
\hline 14. & & Sekolah Alam & $\sqrt{ }$ & - & - \\
\hline 15. & $\begin{array}{l}\text { Fasilitas } \\
\text { Pendukung }\end{array}$ & Menara Pandang & $\sqrt{ }$ & - & - \\
\hline 16. & & Papan petunjuk arah & $\sqrt{ }$ & - & - \\
\hline 17. & & $\begin{array}{l}\text { Papan nama jenis } \\
\text { mangrove }\end{array}$ & $\sqrt{ }$ & - & - \\
\hline 18. & & $\begin{array}{l}\text { Papan plank nama } \\
\text { lokasi }\end{array}$ & $\sqrt{ }$ & - & - \\
\hline 19. & & Teropong burung & -1 & $\sqrt{ }$ & - \\
\hline
\end{tabular}




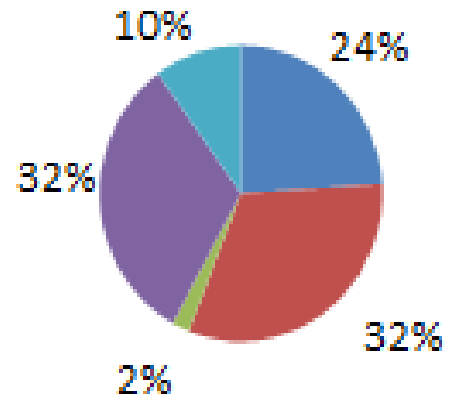

Me lihat Flora \& Fauna

Mangrove

jalan-jalan dikawasan

Me lihat Aktivitas

Masyarakat Lokal

Melihat Pemandangan

Laut

Gambar 2. Distribusi motivasi pengunjung dalam mengunjungi kawasan ekowisata mangrove Pasar Banggi

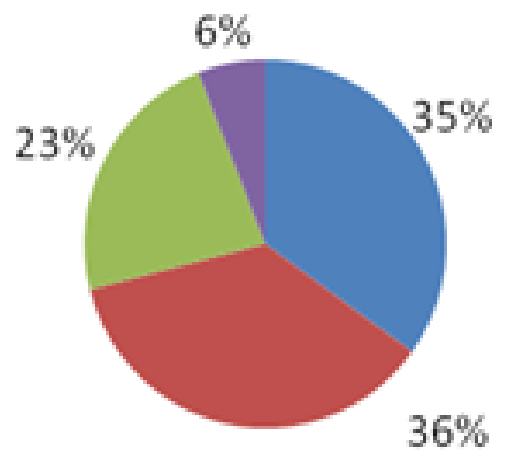

Pengunjung Seorang Diri / Bersama 5 Orang

Pengunjung Rombongan

5-10 Orang

Pengunjung Rombongan

10-20 Orang

Pengunjung Rombongan

$>20$ Orang

Gambar 3. Distribusi asal pengunjung ekowisata mangrove Pasar Banggi

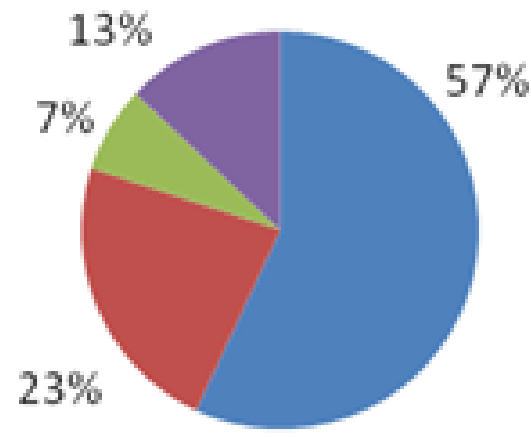

Rp. $100.000,00$ - Rp. $250.000,00$

Rp. $250.000,00$ - Rp. $400.000,00$

1 > Rp. $400.000,00$

$<$ Rp. $100.000,00$

Gambar 4. Distribusi tingkat kemampuan pengeluaran uang untuk aktivitas dkawasan ekowisata mangrove Pasar Banggi

Berdasarkan hasil analisa SWOT didapatkan 7 skala prioritas strategi pengembangan (Tabel 2), yang perlu ditetapkan dalam mengimplementasikan pengembangan ekowisata mangrove di Desa Pasar Banggi yang dikelompokan menjadi 2 prioritas strategi, yaitu diantaranya: (a) Meningkatkan ekonomi dengan pengembangan ekowisata mangrove yang melibatkan masyarakat sekitar dengan melakukan rehabilitasi hutan mangrove untuk upaya konservasi. Menurut Rahmayani dan Achnes (2015), potensi pemanfaatan ekosistem hutan mangrove yang dikembangkan sebagai ekowisata di Bandar Bakau, Kota Dumai, seperti halnya di Dukuh Pandansari, memiliki manfaat peningkatan peluang ekonomi yang berupa: (1) Meningkatkan lapangan kera bagi masyarakat dan penduduk lokal; (2) Meningkatkan pendapatan; (3) Berkembangnya usaha baru, dan berkembangnya ekonomi lokal; (4) Berkembangnya usaha atau kerajinan barang lokal; (5) Meluasnya pemasaran dan peningkatan penerimaan devisa; (6) Meningkatkan standar hidup masyarakat dan mendorong karyawan dan masyarakat untuk 
mempelajari keterampilan; (7) meningkatkan sumber pendanaan untuk perlindungan alam dan pemberdayaan masyarakat lokal pendanaan untuk perlindungan alam dan pemberdayaan masyarakat lokal.

Menurut Nurdin (2011), perlu pendekatan yang komprehensif dalam pelestarian untuk dapat menggabungkan suatu komitmen yang kuat terhadap pelestarian alam serta tanggung jawan sosial ekonomi yang besar kepada masyarakat lokal, atau dapat disebut sebagai perjalanan wisata yang bertanggungjawab. Apabila kawasan hutan mangrove di Pasar Banggi ini dipelihara keberlangsungannya, pasti akan lebih berkembang. Dan potensi ekonomi pun akan muncul seiring dengan bertambahnya jumlah wisatawan yang berkunjung ke kawasan ekowisata mangrove. Seperti pada kawasan ekowisata mangrove di Desa Teluk Pambang, Kecamatan Bantan, Kaupaten Bengkalis (Sari, 2015), Masyarakat sekitar dapat memanfaatkan peluang ekonomi dengan memiliki tradisi ritual semah laut, seni permaian alat music tradisional, membuka lapaklapak mereka yang berisi makanan/minuman atau souvenir khas daerah setempat yang dapat dipromosikan sebagai daya tarik ekowisata di Pasar Banggi. (b) Menjaga kondisi ekosistem mangrove serta keanekaragaman flora dan faunanya dengan melakukan rehabilitasi hutan mangrove untuk upaya konservasi yang melibatkan masyarakat sekitar serta pemerintah maupun lembaga-lembaga non pemerintah yang terkait.

Strategi pengelolaan kawasan pengembangan ekowisata mangrove setelah memperhatikan segala potensi sumberdaya alam dan sumberdaya manusianya di sekitar lokasi penelitian dan digabungkan dengan analisa SWOT maka disusun beberapa rencana strategi yang menjadi prioritas utama dalam pengelolaan kawasan ekosistem mangrove di Desa Pasar Banggi. Dari Matrik SWOT didapatkan tujuh strategi pengelolaan ekosistem mangrove untuk Desa Pasar Banggi, Rembang, namun menurut analisa matrik grand strategy menunjukkan bahwa posisi pengelolaan konservasi ekosistem mangrove di Desa Pasar Banggi berada pada kuadran I.

Strategi pengelolaannya adalah dengan menggunakan strategi agresif, yaitu memaksimalkan kelebihan (strength) yang telah ada dan peluang (opportunity) yang telah teridentifikasi. Strategi ini menjadi prioritas utama adalah karena nilai keterkaitan unsur dalam identifikasi IFAS dan EFAS memberikan nilai yang tertinggi. Unsur kekuatan dan peluang yang mendasari strategi tersebut dirasa adalah yang paling sesuai untuk strategi dalam pengembangan kawasan konservasi mangrove di Desa Pasar Banggi, karena dengan memaksimalkan kekuatan dan peluang yang ada disana program dan kawasan konservasi di Desa Pasar Banggi akan berjalan dengan baik dan sesuai dengan harapan bersama, baik dari pemerintah, swasta dan tentunya oleh masyarakat sekitar yang berhubungan langsung dengan ekosistem mangrove.

Strategi pengelolaan ekosistem mangrove yang menjadi prioritas utama di Desa Pasar Banggi adalah: Penentuan zona dalam kawasan konservasi harus memperhatikan pemilihan dan penempatan kegiatan, alokasi sumberdaya alam serta alokasi ruang dengan memperhatikan aspek sumberdaya alam dan sumberdaya manusianya. Penentuan zona seperti zona inti dan zona pemanfaatan terbatas serta zona yang lainnya dalam upaya pelestarian mangrove. Penentuan zona dalam kawasan ekosistem mangrove Desa Pasar Banggi harus ditentukan karena dalam zona inti dilarang keras untuk melakukan kegiatan pemanfaatan dan dalam zonasi pemenfaatan terbatas hanya boleh melakukan kegiatan pemanfaatan sesuai dengan peraturan. Zonasi bisa didefinisikan sebagai usaha untuk membagi suatu wilayah pada kawasan konservasi menjadi beberapa zona fungsional yang berbeda. Penentuan zona dapat dipergunakan sebagai alat sinergitas spasial dan koordinasi rekomendasi perijinan pemanfaatan perairan dan pesisir, kelebihan yang lain adalah adanya kekuatan hukum yang bersifat spasial dalam pemanfaatan ruang pesisir dan laut (Diposaptono et al., 2009). Penentuan zona di Desa Pasar Banggi harus berdasarkan pada segi ekonomi yaitu sebagai kawasan yang dapat menumbuhkan perekonomian masyarakatnya dan dari segi konservasi yaitu sebagai langkah mempertahankan kelangsungan kondisi alam, sosial, budaya atau kearifan lokal di Desa Pasar Banggi, Rembang. Rencana pengelolaan yang meliputi rencana kerja dalam pengelolaan yang tertulis dan memiliki kekuatan hukum, pengaturan koordinasi, kegiatan yang terpadu dan berkelanjutan, mengkampanyekan pelestarian kepada masyarakat luas secara terus menerus, antara lain dengan mengadakan penyuluhan dan pelatihan. Rencana pengelolaan dengan membuat pengelola yaitu KKMD yang merupakan organisasi lintas sektor yang mampu mencakup SKPD, LSM, swasta dan masyarakat 
sehingga dapat tercipta koordinasi yang baik di lintas sektor yang memiliki kepentingan dengan ekosistem mangrove.

Peran stakeholder sangat penting dalam kegiatan pengelolaan konservasi ekosistem mangrove di Desa Pasar Banggi, mengingat stakeholder sebagai pelaku pembangunan dan pengguna sumberdaya alam. Partisipasi stakeholder di Desa Pasar Banggi cukup baik sehingga dalam rangka pengelolaan konservasi ekosistem mangrove peran serta stakeholder harus terus ditingkatkan supaya kegiatan konservasi ekosistem mangrove dapat berjalan dengan baik. Stakeholder dalam hal ini terdiri dari pemerintah, lembaga non pemerintah, perguruan tinggi dan masyarakat. Keterlibatan masyarakat sangat penting mengingat masyarakat berinteraksi langsung dengan ekosistem mangrove.

Kesadaran masyarakat di Desa Pasar Banggi dapat ditingkatkan dengan memberikan kepercayaan kepada masyarakat dalam mengelola program-program konservasi yang dilaksanakan disana. Menempatkan masyarakatnya pada posisi sebagai pelaku utama sarta stakeholder yang lain sebagai pendukungnya dalam kegiatan konservasi. Masyarakat diajak mulai dari dalam penyusunan rencana kegiatan, penyusunan rencana anggaran, penentuan lokasi,

Tabel 2. Keterkaitan unsur-unsur SWOT yang terdapat dalam setiap strategi yang dihasilkan dan jumlah skor yang didapat dalam pengelolaan potensi ekowisata di Pasar Banggi

\begin{tabular}{|c|c|c|c|c|}
\hline No. & Strategi & $\begin{array}{l}\text { Keterkaitan } \\
\text { Unsur }\end{array}$ & $\begin{array}{l}\text { Jumlah } \\
\text { Skor }\end{array}$ & Prioritas \\
\hline I. & Strategi S-O & & & \\
\hline 1. & $\begin{array}{l}\text { Peningkatan partisipasi stakeholder } \\
\text { terhadap program konservasi ekosistem } \\
\text { mangrove }\end{array}$ & $\mathrm{S} 2, \mathrm{O} 1, \mathrm{O} 2$ & 3,29 & 2 \\
\hline 2 & $\begin{array}{l}\text { Penentuan zona dalam kawasan konservasi } \\
\text { ekosistem mangrove di Desa Pasar Banggi }\end{array}$ & $\mathrm{S}_{1}, \mathrm{~S}_{2}, \mathrm{O}_{1}, \mathrm{O}_{2}$ & 4,52 & 1 \\
\hline II. & Strategi W-O & & & \\
\hline 3. & $\begin{array}{l}\text { Pengadaan sarana dan prasarana } \\
\text { penunjang program konservasi ekosistem } \\
\text { mangrove }\end{array}$ & $W_{1}, O_{2}$ & 1,94 & 4 \\
\hline 4. & $\begin{array}{l}\text { Peningkatan kualitas SDM dan } \\
\text { perekonomian masyarakat yang terkait } \\
\text { program konservasi ekosistem mangrove }\end{array}$ & $\mathrm{W}_{2}, \mathrm{O}_{2}$ & 1,57 & 6 \\
\hline III. & Strategi S-T & & & \\
\hline 5. & $\begin{array}{l}\text { Penguatan perundang-undangan tentang } \\
\text { pengelolaan konservasi ekoswisata } \\
\text { mangrove dalam pemanfaatan ekosistem } \\
\text { mangrove secara berlebih dan penanganan } \\
\text { limbah }\end{array}$ & $S_{2}, T_{1}, T_{2}$ & 2,29 & 3 \\
\hline 6. & $\begin{array}{l}\text { Peningkatan perekonomian masyarakat } \\
\text { setempat dengan keterpaduan pengelolaan } \\
\text { pemanfataan sumber-sumber daya pesisir } \\
\text { yang berkelanjutan }\end{array}$ & $\mathrm{S}_{2}, \mathrm{~T}_{2}$ & 1,39 & 5 \\
\hline IV. & Strategi W-T & & & \\
\hline 7. & $\begin{array}{l}\text { Peningkatan partisipasi masyarakat dan } \\
\text { stakeholder lainnya dalam program } \\
\text { konservasi ekosistem mangrove dan sumber } \\
\text { daya pesisir lainnya secara berkelanjutan } \\
\text { guna mengurangi potensi degradasi } \\
\text { lingkungan pesisir }\end{array}$ & $W_{3}, T_{2}$ & 0,59 & 7 \\
\hline
\end{tabular}


pengadaan bibit, penanaman, pememilharaan hingga pengawasan. Berdasarkan potensi sumberdaya alam yang ada di area ekosistem mangrove strategi yang dapat dilakukan untuk mengembangkan pariwisata mangrove di Desa

Peningkatan potensi ekowisata di Desa Pasar Banggi dapat dilakukan dengan beberapa hal (1) Peningkatan Sumberdaya Manusia : Penyuluhan maupun kegiatan sosialisasi merupakan salah satu metode yang dapat digunakan untuk menyampaikan sesuatu hal yang baru, yaitu: Pertama, mengenai pengelolaan mangrove dari mulai pengenalan jenis-jenis mangrove, manfaat mangrove, jenis-jenis biota yang hidup pada ekosistem mangrove hingga upaya konservasi mangrove. (2) Pengembangan sarana dan prasarana : Sarana prasarana merupakan suatu hal yang sangat penting dalam menunjang kegiatan wisata agar setiap pengunjung yang datang mendapat kemudahan dan merasa puas serta kenyamanan dalam melakukan kegiatan wisata terutama di lokasi ekowisata hutan mangrove di Pasar Banggi. Fasilitas umum yang mendukung kegiatan ekowisata mangrove di Pasar Banggi, yaitu seperti menyediakan informasi terkait dengan hutan wisata mangrove di Pasar Banggi baik berupa peta wilayah, zona yang dapat dikunjungi maupun berbahaya, informasi satwa liar yang hidup disana, gazebo maupun menara pandang yang sudah ada hendaknya lebih diperhatikan (3) Pengembangan promosi wisata mangrove: Daya tarik mangrove dan potensi pasar mancanegara maupun domestik terhadap wisata mangrove sangat tinggi, oleh karena itu perlu adanya optimalisasi potensi yang ada untuk menjadikan mangrove sebagai salah satu objek wisata daratan, contohnya tracking mangrove. (4) Pengembangan kuliner : Keberadaan wisata kuliner yang menarik dan keberadaan souvenir khas daerah menjadi peluang yang dapat menarik minat wisatawan. Pelatihan dan penyuluhan kepada masyarakat menjadi salah satu cara untuk meningkatkan ekonomi secara langsung kepada para pelaku ekonomi, kesempatan kerja dan lebih jauh meningkatkan efektifitas berfungsinya organisasi-organisasisosial kemasyarakatan dalam upaya melindungi keberlanjutan sistem produksi makanan tradisional. (5) Pengembangan potensi pendidikan konservasi: Dengan adanya pemahaman dan peran masyarakat terhadap keberadaan mangrove di lingkungan mereka, akan memberikan nilai tambah dalam memaknai kehidupan pesisir itu sendiri. Pemahaman dan kesadaran akan peran masyarakat lokal dapat dikenalkan, dilatih dan dipraktekkan dalam sebuah program linier seperti sosialisasi pemahaman ekowisata, pelatihan pemanduan wisata atau interpreter ekowisata pemula dengan dibekali materi mengenai mangrove dan ekosistemnya. (6) Menurut Nurdin (2011), bagi masyarakat luar kawasan hutan mangrove di Pasar Banggi, seperti siswa sekolah hingga universitas, dan masyarakat umum, dapat memperoleh informasi dan pendidikan yang baik mengenai fungsi dan manfaat mangrove. Selain itu ekowisata mangrove dapat memberikan pendidikan mengenai pentingnya rehabilitasi hutan mangrove untuk mengurangi kerusakan ekosistem mangrove sebagai upaya konservasi. Melalui perjalanan ekowisata mangrove pengunjung dapat mengetahui ruang lingkup konservasi hutan mangrove yang meliputi usaha perlindungan, pelestarian alam dalam bentuk penyisihan areal sebagai kawasan suaka alam baik untuk perairan laut, pesisir dan hutan mangrove.

Kegiatan konservasi ekosistem mangrove di Desa Pasar Banggi bisa dikatakan baik karena adanya tokoh masyarakat yang memperjuangkan mangrove dan kemudian adanya kelompok tani Sido Dadi Maju yang mendukung kelestarian mangrove dengan membuat peraturan menurut kesepakatan masyarakat dalam mengelola dan melindungi ekosistem mangrove, maka ini dirasa hal positif yang ada di Desa Pasar Banggi yang dapat merubah pola pikir masyarakat yang dulunya hanya bergantung kepada hasil laut dan mengkonversi ekosistem mangrove untuk dijadikan tambak menjadi masyarakat yang peduli akan konservasi mangrove dan membuka kesempatan untuk menambah penghasilan dari kegiatan mencari biota yang ada di ekosistem mangrove untuk dijual dan sebagai penyedia bibit mangrove untuk kegiatan rehabilitasi.

Partisipasi dari pemerintah dan lembaga non pemerintah juga sangat diperlukan dalam program konservasi ekosistem mangrove di Desa Pasar Banggi ini. Pemerintah dalam hal ini diwakilkan oleh Dinas Kelautan dan Perikanan Kabupaten Rembang, Perhutani Kabupaten Rembang, BLH Kabupaten Rembang, BAPPEDA Kabupaten Rembang dan dari pihak lembaga non pemerintah adalah dari Lembaga Masyarakat Lingkungan Hidup, BALAS (Bangkit Lestari dan 
Sentosa), Yayasan BINTARI (Bina Karta Lestari), HNSI (Himpunan Nelayan Seluruh Indonesia), HKR (Himpunan Keluarga Rembang) dan lain-lain saling berkoordinasi untuk mendukung program konservasi ekosistem mangrove di Desa Pasar Banggi. Sedangkan dukungan dari lembaga non pemerintah biasanya berupa rehabilitasi dan pengawasan. Mayoritas pelaksanaan program rehabilitasi ekosistem mangrove hanya sampai kegiatan penanaman mangrove, padahal dengan adanya kegiatan monitoring, control dan evaluasi yang diprogramkan pasca penanaman mangrove akan memberikan peluang besar terpeliharanya mangrove yang telah ditanam.

Partisipasi masyarakat dalam kegiatan monitoring, control dan evaluasi secara mandiri dilakukan tidak terlepas dari program penyuluhan yang rutin dilakukan oleh pemerintah ataupun lembaga non pemerintah pada saat program konservasi dilakukan. Penyuluhan ini merupakan bentuk penghargaan kepada masyarakat sebagai suatu bentuk penyadaran terhadap arti pentingnya ekosistem mangrove untuk kehidupan manusia dan makhluk hidup. Berdasarkan hasil wawancara pribadi dengan Sahal (Ketua Kelompok Tani Sido Dadi Maju, 2012). Strategi pengelolaan kawasan pengembangan ekowisata mangrove setelah memperhatikan segala potensi sumberdaya alam dan sumberdaya manusianya di sekitar lokasi penelitian dan digabungkan dengan analisa SWOT maka disusun beberapa rencana strategi yang menjadi prioritas utama dalam pengelolaan kawasan ekosistem mangrove di Desa Pasar Banggi. Dari Matrik SWOT didapatkan tujuh strategi pengelolaan ekosistem mangrove untuk Desa Pasar Banggi, Rembang, namun menurut analisa matrik grand strategy menunjukkan bahwa posisi pengelolaan konservasi ekosistem mangrove di Desa Pasar Banggi berada pada kuadran I. Strategi pengelolaannya adalah dengan menggunakan strategi agresif, yaitu memaksimalkan kelebihan (strength) yang telah ada dan peluang (opportunity) yang telah teridentifikasi.

\section{KESIMPULAN}

Potensi ekowisata mangrove Pasar Banggi yaitu terdiri dari potensi biologi yang kondisinya masih baik dan potensi fisik yang cukup lengkap. Potensi obyek wisata yang sudah ada dan disediakan untuk ekowisata mangrove antara lain: board walk (jembatan merah) sepanjang 100 meter yang membelah hutan mangrove dari selatan ke utara, tempat parkir, dan akses jalan yang berupa pematang tambak. Sarana pendukung seperti warung makan atau penjual cinderamata masih cukup minim. Hasil analisis SWOT dapat disimpulkan 2 skala prioritas : Peningkatan pengembangan ekowisata mangrove dalam bidang promosi program ekowisata dan penguatan institusi sebagai informasi ilmu pengetahuan ekosistem mangrove. Peningkatan partisipasi stakeholder terhadap pengembangan ekowisata mangrove yang berkelanjutan untuk peningkatan pelayanan terhadap pengunjung

\section{DAFTAR PUSTAKA}

Diposaptono, S., Budiman \& Agung, F., 2009. Menyiasati perubahan iklim di wilayah pesisir dan pulau-pulau kecil. Penerbit Buku Ilmiah Populer.

Giesen, W., 1993. Indonesia's Mangroves: An Update on Remaining Area \& Main Management Issues. Asian Wetland Bureau (AWB).

Kustanti, A. \&Yulia, R.F., 2005. Laporan Pengelolaan Terpadu hutan Mangrove kerjasama: masyarakat, Universitas lampung, dan Kabupaten Lampung Timur. Universitas Lampung. Bandar Lampung.

Nurdin, M. 2011. Wisata Hutan Mangrove Wonorejo: Potensi Ecotourism dan Edutourism Di Surabaya. Jurnal Kelautan. 4(1):11-17.

Rahmayani, H. \& Achnes, S., 2015. Ekowisata Mangrove sebagai Kawasan Perlindungan Sumberdaya Alam dan Nilai Budaya di Bandar Bakau Kota Dumai. Jurnal Online Mahasiswa Bidang IImu Sosial dan IImu Politik, 2(1):1-11. 
Sari, I.P., Yoza, D. \& Sribudiani, E., 2015. Analisis Kelayakan Ekosistem Mangrove Sebagai Objek Ekowisata di Desa Teluk Pambang Kecamatan Bantan Kabupaten Bengkalis. Jurnal Online Mahasiswa Fakultas Pertanian Universitas Riau, 2(1):1-10.

Singarimbun, M. \& Effendi, S., 1989. Metodologi penelitian survei. Jakarta: LP3ES. 